\title{
Suv39h1 Protects from Myocardial Ischemia- Reperfusion Injury in Diabetic Rats
}

\author{
Bo Yang ${ }^{a}$ Jian Yang ${ }^{b}$ Jing Bai Peng Puc Jun Liua Fang Wang ${ }^{a}$ Bing Ruan ${ }^{a}$ \\ aDepartment of Cardiology, Renmin Hospital of Wuhan University, Wuhan, bepartment of Cardiology, \\ the First College of Clinical Medical Sciences, China Three Gorges University, Yichang, ${ }^{,}$Department of \\ Cardiology, the First Affiliated Hospital of Chongqing Medical University, Chongqing, China
}

\section{Key Words}

Suv39h1 • Diabetes $・$ Ischemia/reperfusion injury • Apoptosis $・$ Inflammation

\begin{abstract}
Background: Patients with diabetes are at increased risk of ischemic events. Suv39h1 is a histone methyltransferase that catalyzes the methylation of histone 3 lysine 9 , which is associated with the suppression of inflammatory genes in diabetes. However, the role of Suv39h1 in myocardial ischemia/reperfusion (I/R) injury under diabetic condition has not been evaluated. Methods: To generate diabetic model, male SD rats were fed with $60 \%$ fat diet followed by intraperitoneal injection with $40 \mathrm{mg} / \mathrm{kg}$ streptozotocin. Adenovirus encoding Suv39h1 gene was used for Suv39h1 overexpression. Each rat received injections of adenovirus at five myocardial sites. Three days after gene transfection, each rat was subjected to left main coronary artery occlusion and reperfusion. After $30 \mathrm{~min}$ ischemia and reperfusion for $4 \mathrm{~h}$, the rats were euthanized for real-time PCR, Western blot, immunohistochemical staining, and morphometric analysis. Results: Delivery of Ad-Suv39h1 into the hearts of diabetic rats could markedly increase Suv39h1 expression. Up-regulation of Suv39h1 significantly reduced infarct size and tissue damage after I/R injury, which was associated with protection from apoptosis of cardiac myocytes and reduction of inflammatory response. In addition, compared with injury group, Ad-Suv39h1 led to a decreased activity of mitogen-activated protein kinase family and its down-steam transcriptional factor NF-kB. Conclusion: Overexpression of Suv39h1 results in the de-activation of proinflammatory pathways and reduced apoptosis and myocardial injury. Therefore, Suv39h1 might represent a novel therapeutic strategy to reduce I/R injury
\end{abstract} under diabetic condition. 


\section{Introduction}

The most efficient approach of reducing myocardial infarction is to accelerate reperfusion of the myocardium. However, reperfusion could cause injury to the myocardium through induction of myocardial apoptosis [1]. It is well recognized that diabetic heart is more sensitive to ischemia / reperfusion (I/R) injury [2,3]. Clinical data indicated that patients with diabetes are at increased risk of ischaemic events and diabetes presents an important risk factor to poor outcomes after coronary revascularization [4]. However, the underlying mechanisms by which the myocardium is more prone to I/R injury remain unclear.

Current studies have revealed a relationship between chronic inflammation and increased morbidity and mortality associated with cardiovascular complications in type 2 diabetes [5]. Hyperglycemia has been involved in several diabetic complications via activation of several key signaling pathways which results in inflammatory gene expression [6]. Increased levels of inflammatory cytokines and chemokines participated in diabetic complications and insulin resistance, such as atherosclerosis [7], I/R injury [8], myocardial infarction [9]. In a series of recent experimental studies, it was demonstrated that hyperglycemia can induce specific gene-repressing epigenetic changes [10]. In particular, alteration of histone 3 lysine 9 (H3K9) methylation in the genes promoters was induced by transient hyperglycemia [11, 12]. Suppressor of variegation of 3-9 homolog 1 (Suv39h1) is a histone methyltransferase that catalyzes the methylation of H3K9 [13], which is associated with the suppression of the candidate genes under diabetic condition, including IL-6, TNF- $\alpha$ and MCP-1 $[11,12]$.

Although several researches support a dynamic role for Suv39h1 and H3K9 methylation in inflammatory gene expression in different cell types [11,12,14,15], to our knowledge, the role of Suv39h1 in myocardial I/R injury under diabetic condition has not been evaluated. Thus the major objective of the present study was to assess the role of Suv39h1 in I/Rinduced myocardial apoptosis and inflammation and to address the mechanisms in vivo.

\section{Materials and Methods}

\section{Preparation of Replication-Deficient Adenoviral Vector Ad-Suv39h1}

A serotype 5 adenovirus encoding for green fluorescent protein under the control of the cytomegalovirus promoter was used in the control group (Ad-GFP, VGTC, China). Adenoviral vector encoding Suv39h1 (GenBank accession: NM_001106956.1) was generated using serotype 5 adenovirus. In brief, rat Suv39h1 cDNA was cloned into the shuttle plasmid pDC316 (Ad-GFP, VGTC, China). The resulting plasmid was linearized with Nrul and co-transfected with framework plasmid pBHGlox_E1 (Ad-GFP, VGTC, China) into 293 cells by calcium phosphate/DNA coprecipitation. pBHGlox_E1 is a biologically selected, restriction enzyme-site-loss variant of wild type adenovirus type 5. 293 cells are human embryonic kidney carcinoma cells that have been transformed with the left end of human adenovirus type 5 DNA. Recombinant adenovirus vectors were generated by homologous recombination. Viral plaques were picked and propagated in 293 cells. Viral titer was determined by plaque assay. Viral titer was determined by assessing plaque-forming units (pfu) on 293 cells.

\section{Animal model of diabetic rats}

The investigation conformed to the Guide for the Care and Use of Laboratory Animals published by the US National Institutes of Health, and the protocol was approved by the Institutional Animal Care Committee from Wuhan University, People's Republic of China. The rat model of diabetes was prepared as previously described [16]. In brief, male Sprague-Dawley (SD) rats, 8 weeks of age and weighing about $170 \mathrm{~g}$, were used for all studies. To generate diabetic model, male SD rats were fed with $60 \%$ fat diet for 4 weeks followed by intraperitoneal injection with streptozotocin (STZ, $40 \mathrm{mg} / \mathrm{kg}$ ) for another 2 weeks. Animals had free access to food and water after the STZ injection. Diabetes was considered to be induced once hyperglycemia became evident (blood glucose levels $>16 \mathrm{mM}$ ). 


\section{Animal preparation and experimental designs}

One week before surgery, 45 diabetic rats (200-250 g) were randomly assigned into three groups, namely, sham group (sham) ( $\mathrm{n}=25)$, myocardial I/R group transfected with Ad-GFP (Ad-GFP) ( $\mathrm{n}=25)$, and myocardial I/R transfected with Ad-Suv39h1 (Ad-Suv39h1) $(n=25)$. Adenoviral vectors were injected intramyocardially with a 30-gauge needle at a dose of $2 \times 10^{10} \mathrm{pfu} / \mathrm{rat}$. Each rat received injections of AdGFP or Ad-Suv39h1 at five myocardial sites in left ventricle separated by 2 or $3 \mathrm{~mm}$ around the left anterior descending [17]. Four days after gene transfection, each rat was subjected to left main coronary artery occlusion and reperfusion as described before [17]. In detail, on the fourth day after gene transfer, animals were re-anaesthetised and the chest re-opened. A 6-0 polypropylene suture was passed loosely around the left main artery near its origin. Coronary occlusion was performed by tightening the suture for $30 \mathrm{~min}$. Acute myocardial ischemia was defined successfully on the basis of recording S-T segment changes and ventricular tachycardia on the electrocardiogram. The ischemic area was readily recognized by a cyanotic appearance and a bulging region. The loop was then loosened and the ischemic myocardial area was reperfused for 4 $\mathrm{h}$, as identified on the basis of return of the original color. After $4 \mathrm{~h}$ of reperfusion, the mice were sacrificed and the hearts were harvested.

\section{Determination of infarct size/area at risk}

The hearts were removed and stained with 1\% Evans Blue to determine the risk zone. Each heart was then sliced horizontally to yield 5 slices each approximately $0.2 \mathrm{~cm}$ thick. The slices were incubated in $1.5 \%$ TTC prepared with $200 \mathrm{mmol} / \mathrm{L}$ Tris buffer (pH 7.8) for $15 \mathrm{~min}$ at $37^{\circ} \mathrm{C}$. Viable non-ischaemic myocardium stains blue with TTC. Ischaemic myocardium, which is still viable, stains red with TTC, whereas the necrotic myocardium does not stain and appears pale white. The slices were preserved in $10 \%$ formaldehyde. The apical side of each slice was imaged and the infarct area (white) and the area at risk (red plus white) from each section were measured using an image analyser. The area at risk was expressed as a percentage of the left ventricle, and the area of infarction was expressed as a percentage of the area of the tissue at risk. Furthermore, cardiac troponin $\mathrm{T}$ (TnT) was measured quantitatively with electrochemiluminescence technology (Roche, Mannheim, Germany) as one biomarker to detect the cardiac injury. Blood samples were collected via external jugular vein and centrifuged to obtain plasma samples. TnT was analyzed according to the manufacturer's protocol.

\section{Immunohistochemistry and Histological Evaluation}

4 hours after the operation, the hearts were harvested, fixed in $4 \%$ paraformaldehyde, and then embedded in paraffin. Hematoxylin and eosin (HE) staining was performed using standard protocol. TdT-mediated dUTP nick end labeling assay (TUNEL, (Bipec) was used to detect the apoptosis with immunohistochemistry as described as protocol. Data were calculated as the percentage of total cells within a given area positive for TUNEL staining.

\section{Western blot analysis}

Total protein extracts from rat heart tissue were lysed in lysis buffer according to the manufacturer's protocol (Biovison). Protein concentration was determined by the bicinchoninic acid protein assay (Bipec). Proteins were separated by SDS-polyacrylamide gels and transferred to PVDF membranes. For immunoblotting, PVDF membranes were blocked and probed with antibodies against Suv39h1 (Abcam), phosphorylated p38 MAPK (Cell signaling), total p38 MAPK(Cell signaling), phosphorylated ERK1/2 (Cell signaling), total ERK1/2 (Cell signaling), phosphorylated JNK (Cell signaling), total JNK (Cell signaling), phosphorylated p65 (Cell signaling), total p65 (Cell signaling), IL-6 (Santa Cruz), MCP-1 (Sigma), TNF- $\alpha$ (Santa Cruz), Caspase-3 (Santa Cruz), Caspase-9 (Santa Cruz), Bcl-2 (Santa Cruz), Bax (Santa Cruz), and GAPDH (Santa Cruz) overnight at $4{ }^{\circ} \mathrm{C}$. After three washes, the blots were incubated with peroxidaseconjugated secondary antibodies (Pierce) for $1 \mathrm{~h}$ at room temperature, and subsequently analyzed by ECL detection system.

\section{Quantitative Real-time PCR}

Total RNA was extracted using a commercial RNA isolation kit (Qiagen). For mRNA analysis, RNA (4.0 $\mu \mathrm{g}$ ) was reversed transcribed into cDNA using superscript ${ }^{\circledR}$ III first-strand synthesis system (Invitrogen) according to the manufacturer's instructions. Real-time PCR was performed using Power SYBR_green PCR 


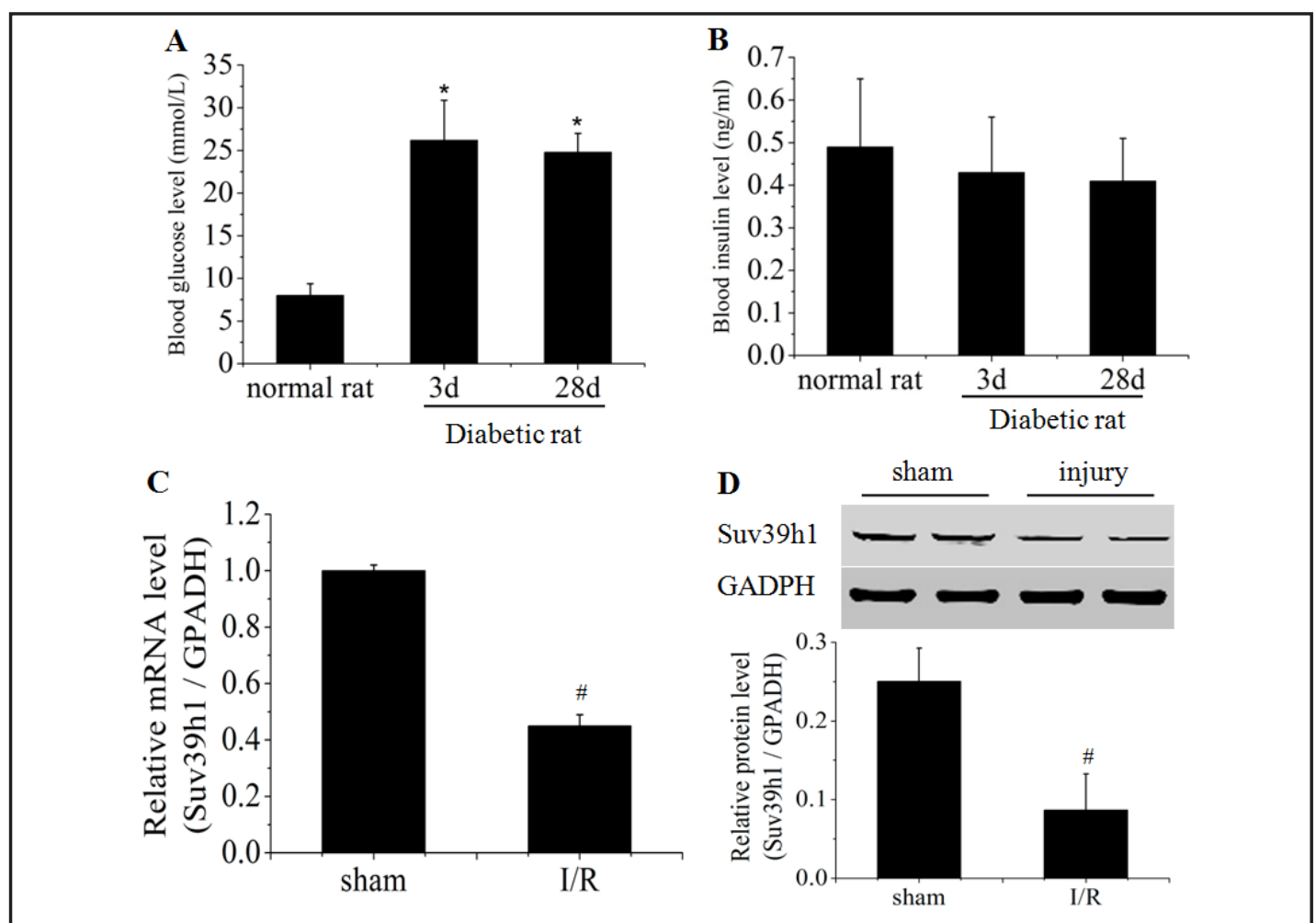

Fig. 1. Suv39h1 expression was decreased after myocardial I/R injury in diabetic rats. Comparison of random blood glucose (A) and plasma insulin (B) levels of diabetic rat models ( $\mathrm{n}=20$ in each group). Diabetic rats were received with procedure of myocardial I/R injury, after $30 \mathrm{~min}$ ischemia and reperfusion for $4 \mathrm{~h}$, mRNA expression of Suv39h1 was examined by real-time PCR (C); protein expression of Suv39h1 was assayed by Western blot (D) $(\mathrm{n}=6) .{ }^{*} p<0.05$ vs. normal rats; ${ }^{*} p<0.05$ vs. sham group.

master mix (Bio-rad), and data were normalized to GAPDH expression by the comparative quantification method $\left(2^{-\triangle \Delta C t}\right)$. Sequence-specific primers used to amplify rat genes were as follows:

Suv39h1, forward primer 5' - ACC AGC CCA ACA TCA AAC -3', reverse primer 5'- GCA ACC CTA TGC GTC TTA-3';

GAPDH, forward primer 5'- GAC ATG CCG CCTG GAG AAA C -3', reverse primer 5'- AGC CCA GGA TGC CCT TTA GT -3'.

\section{Results}

Suv39h1 expression was decreased after myocardial I/R injury in diabetic rats

To detect the alteration of Suv39h1 expression in diabetic heart, experimental rat model of diabetes were generated. Blood glucose levels started to be increased at third day after the injection of STZ, and the level continued to be significantly higher in diabetes rats until 28 days as compared with vehicle-treated rats (Fig. 1A). Plasma insulin was slightly decreased as well (Fig. 1B).Suv39h1 expression was examined in diabetic rat hearts and hearts that underwent I/R injury. After $4 \mathrm{~h}$ of reperfusion, Suv39h1 mRNA level was significantly downregulated about 1.82-fold as compared to sham group without injury (Fig. 1C). The protein level of Suv39h1 was also decreased by $65.5 \%$ in comparison with the values obtained immediately before ischemia (Fig. 1D).

Up-regulation of Suv39h1 reduced infarct size after myocardial I/R injury in diabetic rats

Delivery of Ad-Suv39h1 into the diabetic rat heart could markedly increase Suv39h1 mRNA expression nearly by $98 \%$ (Fig. 2A). A similar pattern of expression was evident for 


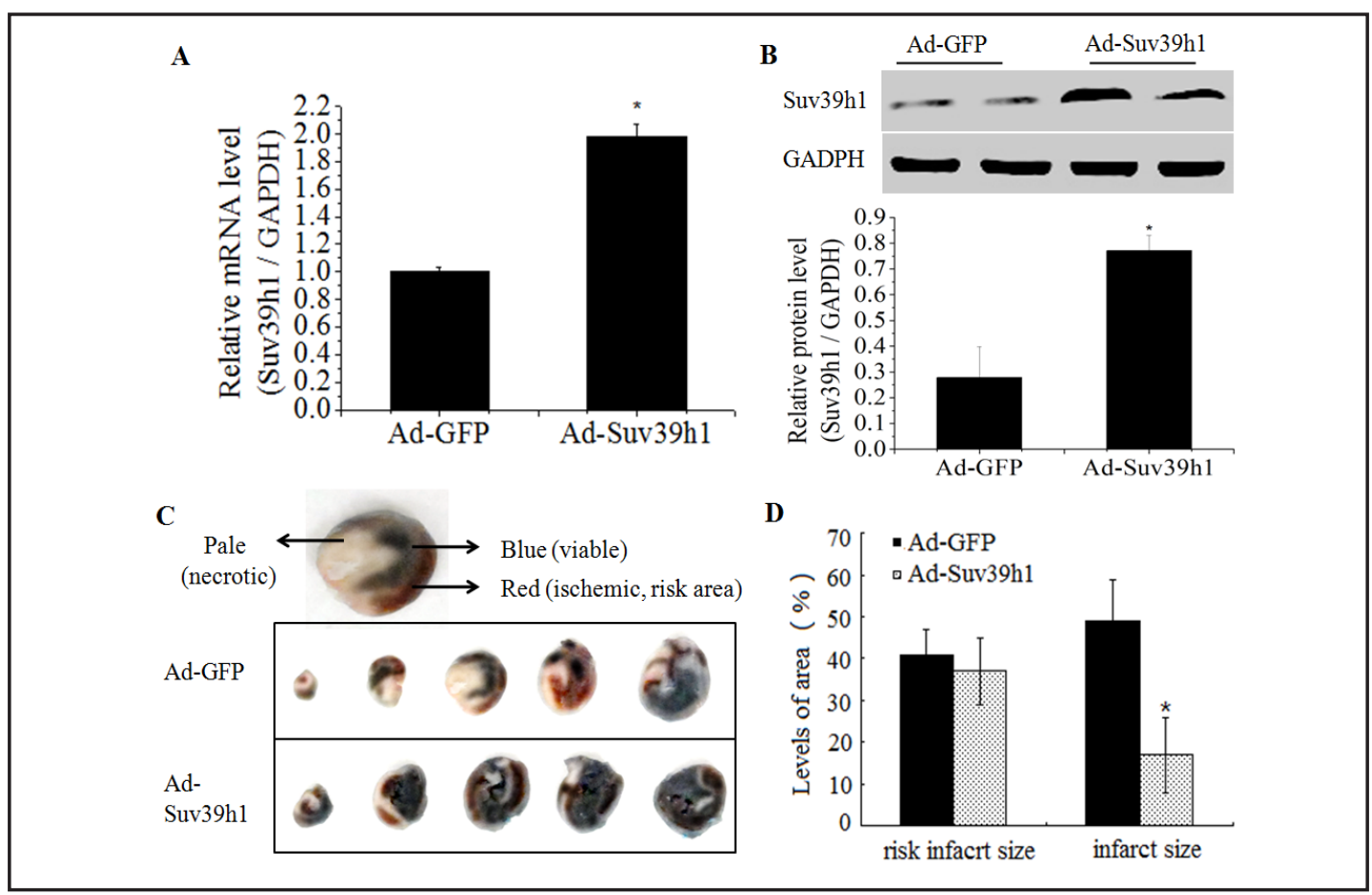

Fig. 2. Up-regulation of Suv39h1 reduced infarct size after myocardial I/R injury in diabetic rats. Ad-GFP or Ad-Suv39h1 was injected intramyocardially at a dose of $2 \times 10^{10} \mathrm{pfu} / \mathrm{rat}$. Four days after gene transfection, each rat was subjected to myocardial I/R injury. (A) mRNA expressions of Suv39h1 was analyzed by real-time PCR (n=6); (B) Protein expression of Suv39h1 was examined by western blot $(n=6)$. (C) A representative TTC staining of infarct size. Normal myocardium is stained dark blue; ischemic area is stained red; infarct area does not stain (pale white). (D) The infarct size was determined by TTC staining. The area at risk was expressed as a percentage of the left ventricle, and the area of infarction was expressed as a percentage of the area of the tissue at risk $(n=12)$. Data are means $\pm \mathrm{SEM},{ }^{*} p<0.05$ vs. Ad-GFP group.

Suv39h1 protein analyzed. Compared with Ad-EGFP control group, Ad-Suv39h1 transfection greatly enhanced Suv39h1 protein levels after I/R injury (Fig. 2B). As shown in Figure 2C and 2D, up-regulation of Suv39h1 reduced infarct size by $66.03 \%$ as compare to Ad-GFP group after $30 \mathrm{~min}$ ischemia and reperfusion for $4 \mathrm{~h}(49.64 \% \pm 9.62 \%$ vs. $16.86 \% \pm 10.11 \%)$, while the size of risk area was insignificantly different between the two groups $(41.02 \% \pm$ $5.12 \%$ vs. $37.04 \% \pm 6.78 \%$, Ad-GFP vs. Ad-Suv39h1). Furthermore, TnT, as a key biomarker for cardiac injury, was also obviously blunted by overexpression of Suv39h1 (20.13 \pm 4.47 $\mathrm{ng} / \mathrm{ml}$ vs. $9.46 \pm 5.89 \mathrm{ng} / \mathrm{ml}$, Ad-GFP vs. Ad-Suv39h1).

Up-regulation of Suv39h1 decreased cardiac myocytes apoptosis after myocardial $I / R$ injury in diabetic rats

TUNEL staining was evaluated in heart slices to assess indication of apoptosis. TUNEL positive cells after I/R injury were higher than that in the sham rats. Up-regulation of Suv39h1 induced an obvious reduction in the percentage of TUNEL-positive cells compared with injury group $(68.73 \pm 6.10 \%$ vs. $45.86 \pm 6.95 \%$, p < 0.05) (Fig. 3A). In agreement with the results of TUNEL assay, Suv39h1 overexpression resulted in the inhibition of caspase activation. Expressions of caspase- 3 and caspase- 9 were decreased by $86.6 \%$ and $81.2 \%$, respectively, by Suv39h1 overexpression after $30 \mathrm{~min}$ ischemia and reperfusion for $4 \mathrm{~h}$. Meanwhile, expression of bcl-2 Protein, an inhibitor of apoptosis was elevated by Suv39h1 overexpression, which was followed with a reduction of Bax, an accelerator of apoptosis. 


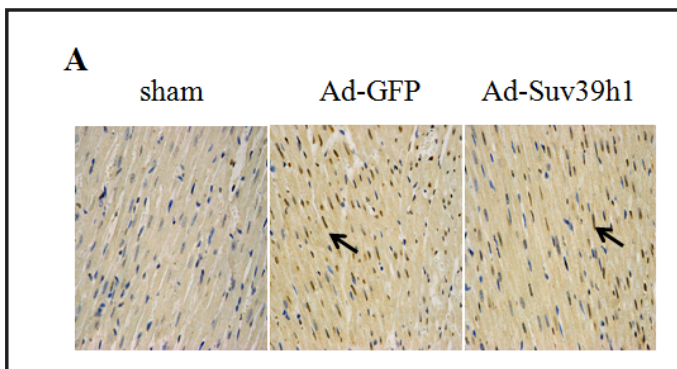

B

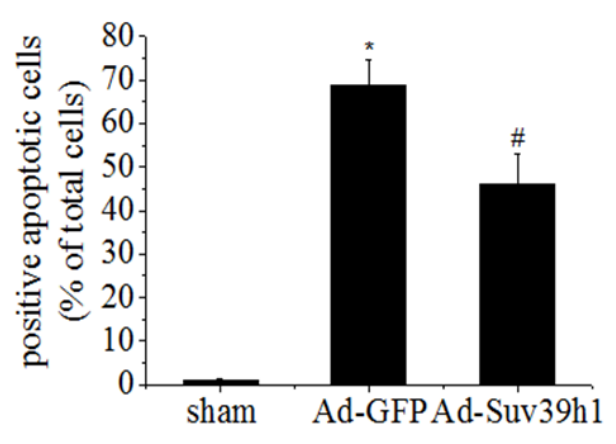

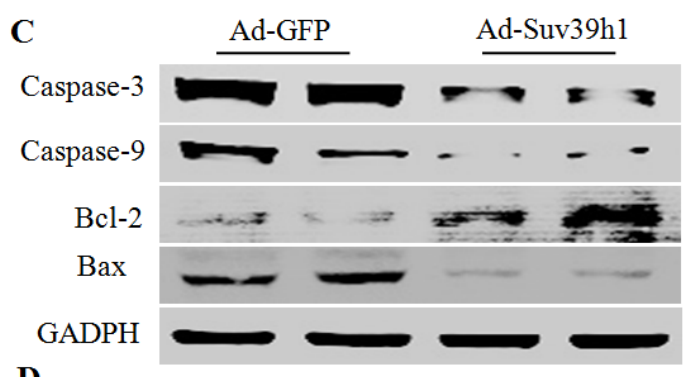

D

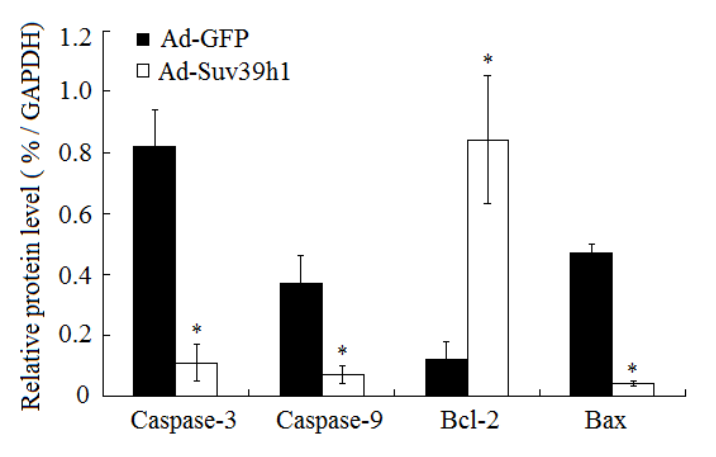

Fig. 3. Up-regulation of Suv39h1 decreased cardiac myocytes apoptosis after myocardial I/R injury in diabetic rats. Four days after Ad-GFP or Ad-Suv39h1 transfection, each rat was subjected to myocardial I/R injury. (A) Heart sections at are representatives of myocardial apoptosis (TUNEL) in the area at risk of left ventricle. Arrowheads indicate apoptotic cells (Original magnification $\times 400$ ). (B) Quantitative analysis of myocardial apoptosis is shown in the histogram. (C) Original representative western blots of Caspase-3, Caspase-9, Bcl-2 and Bax. (D) The corresponding densitometric analyses of these 4 genes are shown as bar graphs. Values are expressed as mean \pm SEM. $(\mathrm{n}=6),{ }^{*} p<0.05$ vs. Ad-GFP group.

Up-regulation of Suv39h1 reduced inflammation after myocardial I/R injury in diabetic rats

Although sham-operated rat showed intact myocardial fibers with transverse striation, cardiac sections from diabetic rats undergoing I/R injury presented with significant features of infarcted tissue, including necrosis, hypereosinophilia, loss of nuclei, and loss of transverse striation, as well as a mixed inflammatory cellular infiltrate; whereas overexpression of Suv39h1 showed a protective role in heart tissue after I/R (Fig. 4A). TNF- $\alpha$, MCP-1 and IL-6 are considered as key mediators in the pathophysiology of myocardial I/R injury [18]. When these three genes were determined in reperfused left ventricles with western blot assay, upregulation of Suv39h1 reduced levels of TNF- $\alpha$, MCP- 1 and IL- 6 by $55.9 \%, 61.3 \%$ and $68.5 \%$, respectively, after 30 min hypoxia and reperfusion for $4 \mathrm{~h}$ as compared with Ad-GFP group (Fig. 4B).

Up-regulation of Suv39h1 attenuated inflammatory signaling pathways after myocardial $I / R$ injury in diabetic rats

Among the mitogen-activated protein kinase (MAPK) family, ERK1/2, p38 and JNK, have been demonstrated to be activated in I/R injury [19]. To study whether Suv39h1 exerts an effect on MAPK activation, these kinases were analyzed by western blot analysis (Fig. 5). I/R induced phosphorylation of ERK1/2, p38 and JNK in the ischemic myocardium (area at risk). In line with a protection from I/R injury shown above, reperfused left ventricles isolated from Suv39h1-overexpression diabetic rats displayed significantly reduced phosphorylation for ERK1/2, p38 and JNK I/R. Suv39h1 did not affect total cellular levels of ERK1/2, p38 and JNK. One downstream effector of MAPK activation is the proinflammatory transcription factor NF- $\kappa B$ known to be activated after I/R injury of the heart [19]. In addition, up-regulation of 


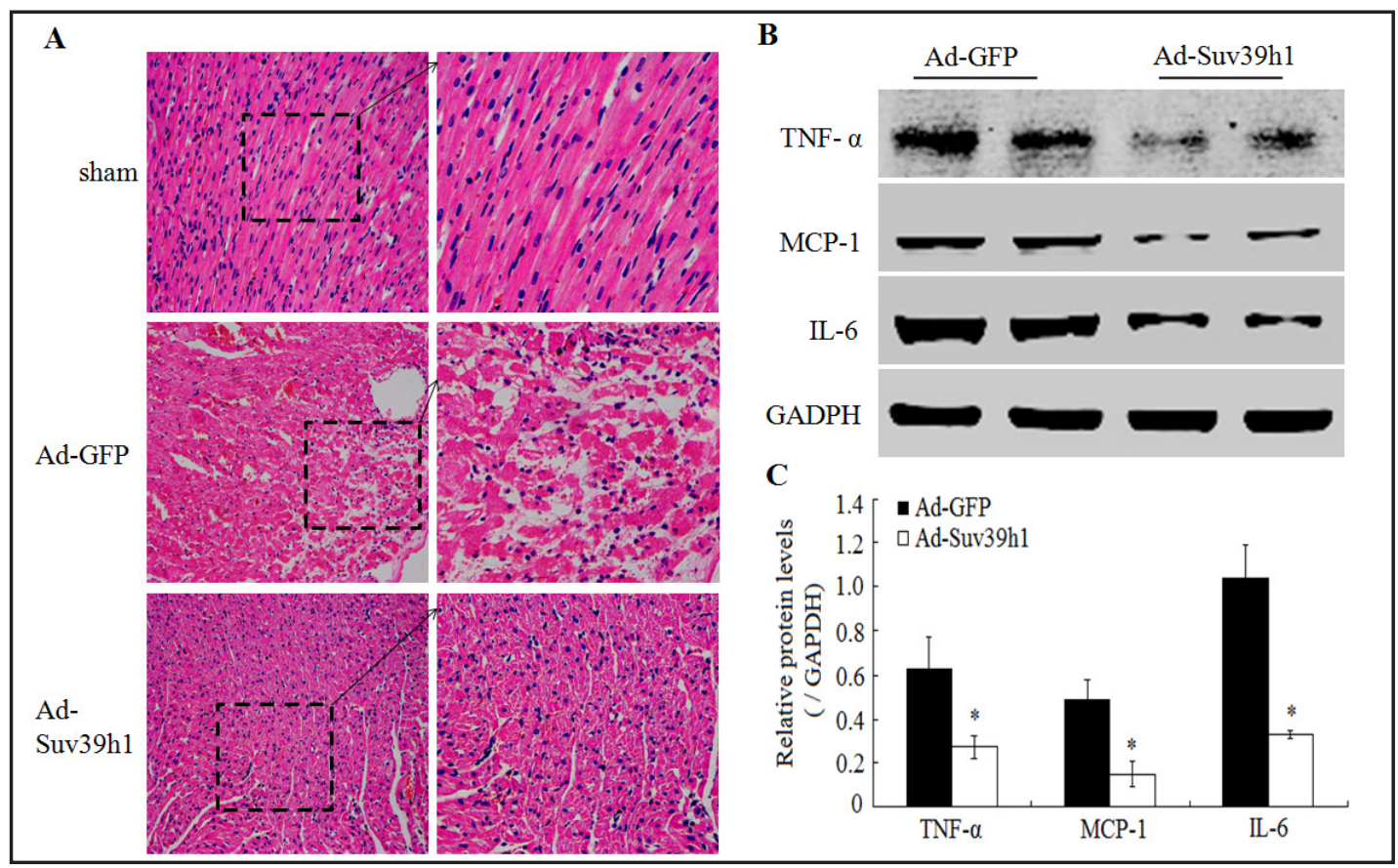

Fig. 4. Up-regulation of Suv39h1 reduced inflammation after myocardial I/R injury in diabetic rats. Four days after Ad-GFP or Ad-Suv39h1 transfection, each rat was subjected to myocardial I/R injury. (A) Heart sections at are representatives of HE in the area at risk of left ventricle. (Original magnification $\times 200$ ). (B) Original representative western blots of TNF- $\alpha$, MCP-1 and IL-6. (C) The corresponding densitometric analyses of these 3 genes are shown as bar graphs. Values are expressed as mean \pm SEM. $(n=6),{ }^{*} p<0.05$ vs. Ad-GFP group.

Suv39h1 inhibited I/R-induced phosphorylation of NF-kB p65 in the ischemic myocardium. However, the total level of p65 was not significantly affected by Suv39h1.

\section{Discussion}

In this study, we have demonstrated that Suv39h1 is a powerful regulator of I/R Injury of the heart in diabetic condition. This conclusion is based on several evidences. First, Suv39h1 expression was decreased during the processes of myocardial I/R Injury. Second, overexpression of Suv39h1 suppressed cardiac myocytes apoptosis and reduced infarct size after myocardial I/R Injury. Third, the cardioprotection induced by overexpression of Suv39h1 involved reduction of inflammation and expression of inflammatory factors. During this process, MAPK/ NF- $\kappa B$ signaling pathway, accounting for inflammatory responses, was attenuated by Suv39h1.

Data from various clinical trials indicate that diabetes complications continue to develop and progress even in patients who have managed to improve their glucose control, a phenomenon referred to as hyperglycemic memory [20]. Recent studies demonstrated a link between epigenetic changes such as H3K9 methylation and metabolic memory [11, 21], which was presented as enhanced levels of inflammatory cytokines and sustained vascular inflammation [11]. In particular, Suv39h1 plays an important role in reduction of promoter H3K9 methylation repressive mark and then participated in metabolic memory [11]. These results were tested in vascular smooth muscle cells (VSMC) derived from type 2 diabetic mice [11]. However, it is of interest that the effect of Suv39h1 on diabetic heart has not been reported so far. Such an effect could be important because chronic inflammation is significantly accelerated in diabetic heart as well and the benefits from glucose-lowering 


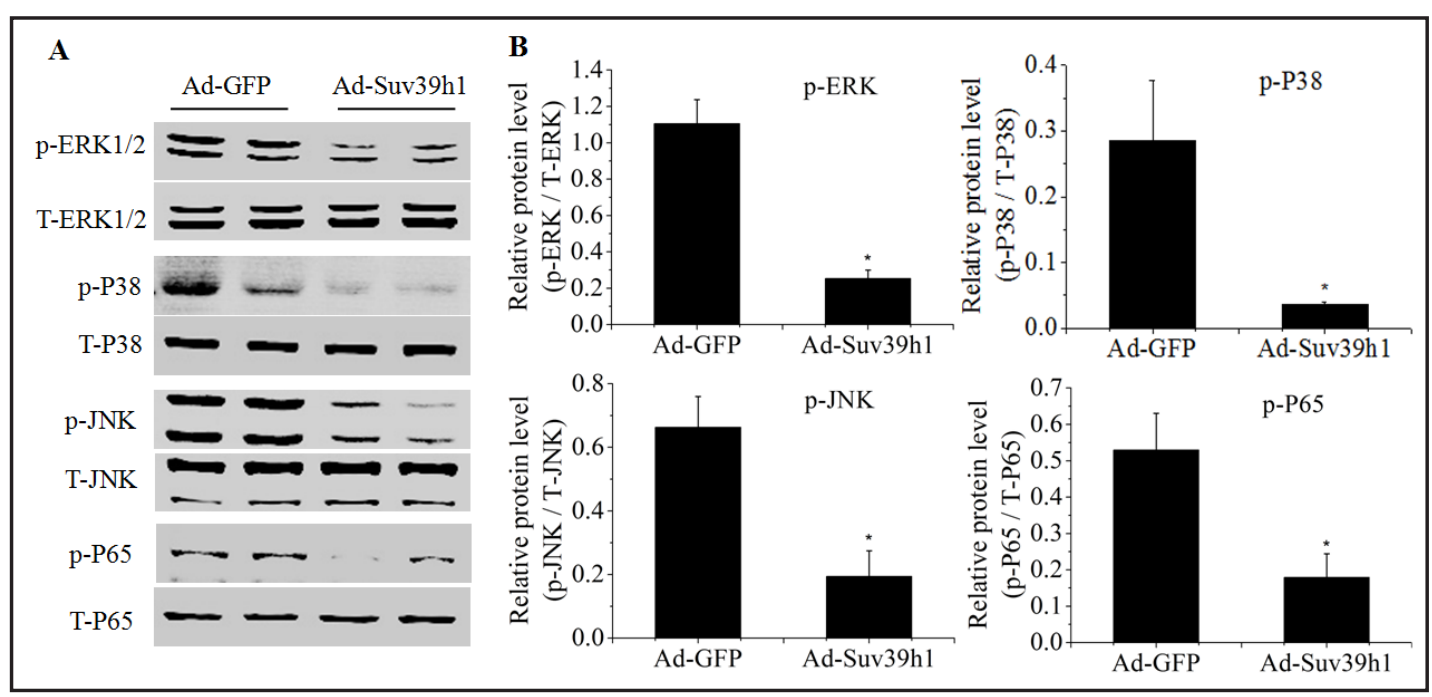

Fig. 5. Up-regulation of Suv39h1 attenuated MAPK / NF-кB pathway after myocardial I/R injury in diabetic rats. (A) Original representative western blots of phosphorylated ERK1/2, p38 MAPK, JNK1/2 and p65; total levels of ERK1/2, p38 MAPK, JNK1/2 and p65. (B) The corresponding densitometric analyses of these genes are shown as bar graphs. Values are expressed as mean \pm SEM. $(\mathrm{n}=6),{ }^{*} p<0.05$ vs. Ad-GFP group.

approach remain contradictory in some clinical studies [22, 23]. Therefore, in this study, firstly we focused on the alteration of Suv39h1 expression after I/R injury in diabetic heart. Our results indicated that Suv39h1 expression was decreased after myocardial I/R injury. These results revealed a same tendency of Suv39h1expression in I/R injury-heart when compared with that in diabetic VSMCs. Based on these data, it's speculated that Suv39h1 might be reduced by diabetic condition throughout the whole cardiovascular system.

In this study, one major question was how overexpression of Suv39h1 exerts its protective role after I/R injury in diabetic heart. Apoptosis in the heart has been implicated in cardiac failure, anthracycline-induced cardiotoxicity, and overstretching of myocytes [24]. Myocardial I/R injury leads to cell death, which is believed to occur through apoptosis and necrosis [25]. In fact, apoptosis was the predominant mode of cardiac cell death induced by coronary artery occlusion. It's well widely accepted that inhibition of apoptosis is beneficial to protect myocardial I/R injury [25]. Apoptosis is positively and negatively regulated by the Bcl-2 family of proteins [26]. Proapoptotic proteins include Bax, Bak, Bcl-XS, Bad, Bid, Bik, Bim, Hrk, and Bok, whereas antiapoptotic proteins include Bcl-2, Bcl-XL, Bcl-w, Mcl-1, and A1/Bfl-1 [26]. In addition, apoptosis is reported to be involved in the initiation of the caspase cascade, including activation of caspase- 8 by cell surface death receptors and the mitochondrial pathway with subsequent caspse-3 and caspase-9 activation [27]. Our results indicated that overexpression of Suv39h1 led to an anti-apoptotic effect on cardiac cell apoptosis induced by I/R injury through regulation of caspase pathways and Bcl-2 family of proteins. These results revealed that Suv39h1 played an important role in making life or death choices in myocardial cell.

Inflammation, as a key potential mediator, has been proposed to underlie myocardial I/R injury. It is generally believed that excessive expression of inflammatory factors, TNF- $\alpha$, MCP-1 and IL-6, could induce myocardial apoptosis. Our study demonstrated that Suv39h1 has the ability of reducing expression of these three genes. Therefore, we suspected that the anti-apoptotic role of Suv39h1 in myocardial I/R injury might be associated with its anti-inflammatory effect. Previous study found that H3K9 methylation and Suv39h1 play important roles in inflammatory gene repression and silencing in diabetic VSMCs [11]. Mechanisms include assembly of repressive complexes at H3K9 methylation sites including HP1 $\alpha$ and HDACs [11]. This promotes H3K9 methylation formation to further amplify repression. Reduced Suv39h1/Suv39h1-mediated H3K9 methylation on promoters of 
inflammatory genes, including IL-6, MCSF, MCP-1 and TNF- $\alpha$ may lead to loss of repressive proteins and formation of open chromatin poised for transcriptional activation as noted in the diabetic condition [11]. Besides this direct regulation at the transcriptional level through epigenetic modulation, our study found that in diabetic heart Suv39h1 might have another indirect effect on anti-inflammation via traditional signaling pathways. Accumulating evidence indicates that myocardial inflammatory cytokine production involves MAPK signaling and downstream effectors NF- $\kappa$ B. The MAPK cascade consists of a sequence of successively acting kinases, including p38, JNK and ERK and is initiated in cardiac myocytes by various stimuli [19]. Once activated, MAPK phosphorylate a wide array of numerous transcriptional factors, such as NF- $\kappa \mathrm{B}$, resulting in the expression of inflammatory genes [19]. Therefore it's possible that inflammation after I/R injury in diabetic heart is regulated in part by Suv39H1 expression and subsequent activation of MAPK and NF- $\kappa B$. Our data are in agreement with this hypothesis that Suv39h1 level was decreased after myocardial I/R injury and overexpression of Suv39h1 reduced inflammatory gene expression through deactivation of phosphorylation of p38, JNK, ERK and NF- $\kappa B$ signaling pathway.

Taken together, Suv39h1 plays a major role after I/R injury in diabetic heart. Overexpression of Suv39h1 results in the de-activation of proinflammatory pathways and reduced apoptosis and myocardial injury. Therefore, Suv39h1 might represent a novel therapeutic strategy to reduce I/R injury under diabetic condition.

\section{Acknowledgments}

This work was supported by Natural Science Foundation of Hubei Province of China (No. 2012FFB04305).

\section{Refereces}

Yellon DM, Hausenloy DJ: Myocardial reperfusion injury. N Engl J Med 2007;357:1121-1135.

Heather LC, Clarke K: Metabolism, hypoxia and the diabetic heart. J Mol Cell Cardiol 2011;50:598-605.

Peake BF, Nicholson CK, Lambert JP, Hood RL, Amin H, Amin S, Calvert JW: Hydrogen sulfide preconditions the $\mathrm{db} / \mathrm{db}$ diabetic mouse heart against ischemia-reperfusion injury by activating Nrf2 signaling in an Erkdependent manner. Am J Physiol Heart Circ Physiol 2013;304:H1215-H1224.

4 Schnell 0, Erbach M, Hummel M: Primary and secondary prevention of cardiovascular disease in diabetes with aspirin. Diab Vasc Dis Res 2012;9:245-255.

-5 Stehouwer CD, Gall MA, Twisk JW, Knudsen E, Emeis JJ, Parving HH: Increased urinary albumin excretion, endothelial dysfunction, and chronic low-grade inflammation in type 2 diabetes: progressive, interrelated, and independently associated with risk of death. Diabetes 2002;51:1157-1165.

-6 Evans JL, Goldfine ID, Maddux BA, Grodsky GM: Oxidative stress and stress-activated signaling pathways: a unifying hypothesis of type 2 diabetes. Endocr Rev 2002;23:599-622.

-7 Kanter JE, Kramer F, Barnhart S, Averill MM, Vivekanandan-Giri A, Vickery T, Li LO, Becker L, Yuan W, Chait A, Braun KR, Potter-Perigo S, Sanda S, Wight TN, Pennathur S, Serhan CN, Heinecke JW, Coleman RA, Bornfeldt KE: Diabetes promotes an inflammatory macrophage phenotype and atherosclerosis through acyl-CoA synthetase 1. Proc Natl Acad Sci USA 2012;109:E715-E724.

-8 La Bonte LR, Davis-Gorman G, Stahl GL, McDonagh PF: Complement inhibition reduces injury in the type 2 diabetic heart following ischemia and reperfusion. Am J Physiol Heart Circ Physiol. 2008; 294: H1282-H1290.

-9 Marfella R, Siniscalchi M, Esposito K, Sellitto A, De Fanis U, Romano C, Portoghese M, Siciliano S, Nappo F, Sasso FC, Mininni N, Cacciapuoti F, Lucivero G, Giunta R, Verza M, Giugliano D: Effects of stress hyperglycemia on acute myocardial infarction: role of inflammatory immune process in functional cardiac outcome. Diabetes Care 2003;26:3129-3135. 
10 Villeneuve LM, Natarajan R: The role of epigenetics in the pathology of diabetic complications. Am J Physiol Renal Physiol 2010;299:F14-F25.

-11 Villeneuve LM, Reddy MA, Lanting LL, Wang M, Meng L, Natarajan R: Epigenetic histone H3 lysine 9 methylation in metabolic memory and inflammatory phenotype of vascular smooth muscle cells in diabetes.Proc Natl Acad Sci USA 2008;105:9047-9052.

12 Chen X, El Gazzar M, Yoza BK, McCall CE: The NF-kappaB factor RelB and histone H3 lysine methyltransferase G9a directly interact to generate epigenetic silencing in endotoxin tolerance. J Biol Chem 2009;284:27857-27865.

13 Martin C, Zhang Y: The diverse functions of histone lysine methylation. Nat Rev Mol Cell Biol 2005;6:838849.

14 Zhou S, Chen HZ, Wan YZ, Zhang QJ, Wei YS, Huang S, Liu JJ, Lu YB, Zhang ZQ, Yang RF, Zhang R, Cai H, Liu DP, Liang CC: Repression of P66Shc expression by SIRT1 contributes to the prevention of hyperglycemiainduced endothelial dysfunction. Circ Res 2011;109:639-648.

- 15 Kim YR, Kim CS, Naqvi A, Kumar A, Kumar S, Hoffman TA, Irani K: Epigenetic upregulation of p66shc mediates low-density lipoprotein cholesterol-induced endothelial cell dysfunction. Am J Physiol Heart Circ Physiol 2012;303:H189-H196.

16 Uemura S, Matsushita H, Li W, Glassford AJ, Asagami T, Lee KH, Harrison DG, Tsao PS: Diabetes mellitus enhances vascular matrix metalloproteinase activity: role of oxidative stress. Circ Res 2001;88:1291-1298.

17 Suzuki K, Murtuza B, Smolenski RT, Sammut IA, Suzuki N, Kaneda Y, Yacoub MH: Overexpression of interleukin-1 receptor antagonist provides cardioprotection against ischemia-reperfusion injury associated with reduction in apoptosis. Circulation 2001;104:S I308-I3.

-18 Aoyagi T, Kusakari Y, Xiao CY, Inouye BT, Takahashi M, Scherrer-Crosbie M, Rosenzweig A, Hara K, Matsui T: Cardiac mTOR protects the heart against ischemia-reperfusion injury. Am J Physiol Heart Circ Physiol 2012;303:H75-H85.

19 Armstrong SC: Protein kinase activation and myocardial ischemia/reperfusion injury. Cardiovasc Res 2004;61:427-436.

20 Ihnat MA, Thorpe JE, Ceriello A: Hypothesis: the 'metabolic memory', the new challenge of diabetes. Diabet Med 2007;24:582-586.

21 Brasacchio D, Okabe J, Tikellis C, Balcerczyk A, George P, Baker EK, Calkin AC, Brownlee M, Cooper ME, El-Osta A: Hyperglycemia induces a dynamic cooperativity of histone methylase and demethylase enzymes associated with gene-activating epigenetic marks that coexist on the lysine tail. Diabetes 2009;58:12291236.

22 ADVANCE Collaborative Group, Patel A, MacMahon S, Chalmers J, Neal B, Billot L, Woodward M, Marre M, Cooper M, Glasziou P, Grobbee D, Hamet P, Harrap S, Heller S, Liu L, Mancia G, Mogensen CE, Pan C, Poulter N, Rodgers A, Williams B, Bompoint S, de Galan BE, Joshi R, Travert F: Intensive blood glucose control and vascular outcomes in patients with type 2 diabetes. N Engl J Med 2008;358:2560-2572.

$\checkmark 23$ Action to Control Cardiovascular Risk in Diabetes Study Group, Gerstein HC, Miller ME, Byington RP, Goff DC Jr, Bigger JT, Buse JB, Cushman WC, Genuth S, Ismail-Beigi F, Grimm RH Jr, Probstfield JL, Simons-Morton DG, Friedewald WT: Effects of intensive glucose lowering in type 2 diabetes. N Engl J Med 2008;358:25452559.

24 Haunstetter A, Izumo S: Apoptosis: basic mechanisms and implications for cardiovascular disease. Circ Res 1998;82:1111-1129.

-25 Zhao ZQ, Morris CD, Budde JM, Wang NP, Muraki S, Sun HY, Guyton RA: Inhibition of myocardial apoptosis reduces infarct size and improves regional contractile dysfunction during reperfusion. Cardiovasc Res 2003;59:132-142.

26 Gustafsson AB, Gottlieb RA: Bcl-2 family members and apoptosis, taken to heart. Am J Physiol Cell Physiol 2007;292:C45-C51.

27 Harwood SM, Yaqoob MM, Allen DA: Caspase and calpain function in cell death: bridging the gap between apoptosis and necrosis. Ann Clin Biochem 2005;42:415-431. 